\title{
Cardiovascular Risk Factors in Patients with Chronic Kidney Disease Under Conservative Treatment
}

\author{
Cássia Oliveira ${ }^{\oplus}$, Priscila Moreira de Lima Pereira ${ }^{\oplus}$, Iris Teixeira Soares ${ }^{\oplus}$, Melina Gabriela Monteiro ${ }^{\oplus}$, Marcus \\ Gomes Bastos ${ }^{\oplus}$, Ana Paula Carlos Cândido ${ }^{\circledR}$
}

Universidade Federal de Juiz de Fora, Juiz de Fora, MG - Brazil.

\section{Abstract}

Background: Cardiovascular disease (CVD) is commonly associated with chronic kidney disease (CKD). These diseases have a significant impact on life expectancy. Individuals with CKD are more likely to die from CVD than to progress to end-stage kidney disease.

Objective: To assess cardiovascular risk factors of patients with CKD under conservative treatment.

Methods: This was an observational, cross-sectional study. Socioeconomic, anthropometric, biochemical, and physical inactivity data were assessed, and 10-year risk for CVD were estimated using the Framingham Score in patients with CKD under conservative treatment. For statistical analysis, the Student's t-test and Pearson's chi-square test were performed.

Results: A total of 172 individuals were evaluated, $57 \%$ of whom were male, with an average age of $68.85 \pm 11.41$ years. The prevalence of hypertension and diabetes were $87.2 \%$ and $53.5 \%$, respectively; $62.2 \%$ were physically inactive; $9.9 \%$ of men were smokers and $12.8 \%$ consumed alcohol. According to BMI, $82.4 \%$ of adults $<60$ years old and $60.6 \%$ of those older than 60 years were overweight. High waist circumference and a high waist-hip ratio were highly prevalent in females $(91.9 \%$ and $83.8 \%$, respectively) and males (64.3\% and $39.8 \%$, respectively); $92.4 \%$ had a high body fat percentage and $73.3 \%$ high uric acid levels. According to the Framingham score, 57\% have a medium or high risk of developing CVD in 10 years.

Conclusion: There was a high prevalence of cardiovascular risk factors in the population studied. The assessment of cardiovascular risk factors in patients with CKD makes it possible to guide the conduct of health professionals to prevent mortality from cardiovascular causes. (Int J Cardiovasc Sci. 2021; 34(2):170-178)

Keywords: Renal Insufficiency, Chronic; Risk Factors; Cardiovascular Diseases/complications; Adults; Hypertension; Diabetes Mellitus; Anthropometry; Abdominal Circumference.

\section{Introduction}

Chronic kidney disease (CKD) is defined as having an abnormal kidney structure or function for three months or longer, which can be aggravated by the progression of disease and lead to irreversible kidney failure. ${ }^{1}$ It is a growing public health problem, with increasing morbidity and mortality in Brazil and worldwide. ${ }^{2,3}$

Cardiovascular disease (CVD) is commonly associated with CKD. When combined, these conditions have a significant impact on life expectancy, since individuals with CKD are more likely to die from CVD than to progress to end-stage renal disease. ${ }^{4}$ An important maker of this association is glomerular filtration rate (GFR), since GFR reduces the percentage of mortality and cardiovascular events increase ${ }^{5}$.

The main cause of kidney disease is diabetic nephropathy and hypertensive nephrosclerosis, both accelerated by smoking and dyslipidemia; thus, the higher risk of CVD among CKD patients is secondary to accumulation of risk factors. ${ }^{6}$ In addition, increased waist circumference (WC) and overweight further increases this risk, as these factors are associated with a greater likelihood of cardiovascular events. ${ }^{7-9}$ 
In addition to anthropometric measurements, it is important to check some biochemical parameters, such as the lipid profile,$^{10}$ uric acid levels, ${ }^{11}$ glycated hemoglobin (HbA1C) and blood glucose values, to prevent the progression of CKD and the risk of developing CVD. ${ }^{12}$

The Framingham Risk Score is a tool widely used for calculation of cardiovascular risk and estimation of the risk of developing CVD in ten years. It has been applied for risk stratification, making it possible to target specific groups of patients who will benefit from drug therapy as a form of primary intervention in CVD prevention. ${ }^{13,14}$

The aim of this study was to assess cardiovascular risk factors in patients with CKD under conservative treatment in a secondary care hospital.

\section{Methods}

This was an observational, cross-sectional study on the cardiovascular risk factors in CKD patients under conservative treatment. The inclusion criteria were patients with stages 3,4 or $5 \mathrm{CKD},{ }^{1}$ aged over 20 years, attending (i.e., not the first consultation) a secondary care center for chronic diseases in Juiz de Fora, Brazil. The exclusion criteria were presence of metabolic diseases, such as cancer, AIDS, chronic obstructive pulmonary disease, among others; amputation of a limb; use of a wheelchair; and use of a pacemaker.

For sample calculation, the population covered by the service $(805,722),{ }^{15}$ the prevalence of CKD stages 3 to $5(10.6 \%){ }^{16}$ confidence limits of $5 \%$ and confidence interval of $95 \%$ were considered, yielding a sample of 146 individuals. This sample was calculated using the Epi Info software. Considering a loss of $15 \%$, we chose to evaluate at least 169 individuals.

Socioeconomic data were collected through questionnaires, and nutritional status were evaluated by anthropometric measurements, bioelectrical impedance analysis, and biochemical tests. For physical activity level, those who reported at least 150 minutes of physical activity weekly were considered as physically active. ${ }^{17}$

Height was measured using a portable stadiometer, and weight was measured using a Tanita BC-553 Ironman ${ }^{\circledR}$ body composition monitor. Then, body mass index (BMI) was calculated and classified according to the World Health Organization (WHO) ${ }^{9}$ criteria for adults and the elderly. ${ }^{18}$
Body fat percentage (BF\%) was measured using the Fresenius Medical Care body composition monitor, and classified according to Lohman and Champaign, 1992. ${ }^{19}$

WC was measured as the smallest circumference between the lowest rib and the iliac crest and classified according to the WHO criteria. ${ }^{9}$ Hip circumference was measured at the widest area of the hips at the greatest protuberance of the buttocks; the waist-hip ratio (WHR) was then calculated and classified according to the WHO. ${ }^{9}$

Regarding biochemical tests, fasting glycemia, total cholesterol (TC), high-density lipoprotein cholesterol (HDL-c), low-density lipoprotein cholesterol (LDL-c), triglycerides (TG), uric acid and $\mathrm{HbA} 1 \mathrm{C}$ were evaluated, which were classified according to the reference values. ${ }^{20}$ For this, patients were asked to bring, on the day of the anthropometric assessment, the last tests performed within the last 90 days.

Blood pressure was measured using the auscultatory method, with an aneroid sphygmomanometer, properly calibrated. The values of systolic blood pressure (SBP) and diastolic blood pressure (DBP) were classified according to the $7^{\text {th }}$ Brazilian Guideline for Hypertension. ${ }^{21}$

Glomerular filtration rate (GFR) was estimated by the CKD-EPI formula, ${ }^{22}$ and classified according to the KDIGO (2012) guidelines. ${ }^{1}$

The Framingham score was used to estimate the cardiovascular risk; the sum of scores was performed based on the variables: sex, age, smoking, diabetes mellitus, HDL-c, TC, SBP, DBP and then classified as low, medium and high risk of developing cardiovascular disease in the next ten years. ${ }^{23}$

\section{Statistical analysis}

First, an exploratory analysis was carried out to verify the integrity (coherence) of the data. Quantitative variables were analyzed for the presence of outliers and the Kolmogorov-Smirnov test was used to verify the normality of data distribution.

Descriptive analysis of the sample was carried out by sex. Continuous variables were expressed as mean \pm standard deviation and compared using the unpaired Student's t-test. The categorical variables, on the other hand, were described as absolute and relative frequencies, and compared, by sex and the Framingham score classification, using the Pearson's chi-square test. 
The SPSS version 20.0 software was used, and the level of significance adopted was $5 \%$.

The study was approved by the research ethics committee of Juiz de Fora Federal University Teaching Hospital (submission number: 1.147.858).

\section{Results}

The sample consisted of 172 participants ( $57 \%$ male), with mean age of $68.85 \pm 11.41$ years, $80.2 \%$ were elderly.

Table 1 shows the general characteristics of the sample, including age, GFR, and anthropometric, biochemical and blood pressure data stratified by sex. Mean values of BMI, BF\%, HDL-c, LDL-c and TC were higher in women, whereas WHR was higher in men. In both sexes, high mean values (above recommendations) were found for BMI, uric acid, fasting glucose and $\mathrm{HbA1C}$ for diabetics. Mean values of lipid parameters were within or close to the reference values for both sexes, as well as fasting blood glucose, $\mathrm{HbA1C}$ for non-diabetics, and SBP and DBP values.

The frequency of cardiovascular risk factors by sex is shown in Table 2. The frequency of diabetes mellitus (DM) and arterial hypertension was high in both men and women, and $50 \%$ of patients had both diseases. Most patients (51.5\%) had CKD stage 3B, and most participants were physically inactive $(62.2 \%)$. Smoking habit was more prevalent in males (15.3\%) than in females $(2.7 \%)$.

Table 1 - General characteristics of chronic kidney disease patients under conservative treatment stratified by sex, Juiz de Fora, Brazil

\begin{tabular}{|c|c|c|c|}
\hline Characteristics & Female & Male & $\mathbf{p}^{\varepsilon}$ \\
\hline Age (years) & $67.88 \pm 12.84$ & $69.59 \pm 10.20$ & 0.347 \\
\hline GFR $\left(\mathrm{ml} / \mathrm{min} / 1.73 \mathrm{~m}^{2}\right)$ & $32.64 \pm 11.42$ & $34.60 \pm 11.58$ & 0.271 \\
\hline BMI $\left(\mathrm{kg} / \mathrm{m}^{2}\right)$ Adults $<60$ years & $31.33 \pm 7.12$ & $30.57 \pm 6.59$ & 0.756 \\
\hline BMI $\left(\mathrm{kg} / \mathrm{m}^{2}\right)$ Adults $\geq 60$ years & $29.85 \pm 5.16$ & $27.78 \pm 4.89$ & 0.019 \\
\hline Waist circumference $(\mathrm{cm})$ & $95.84 \pm 12.90$ & $99.01 \pm 12.95$ & 0.113 \\
\hline WHR & $0.90 \pm 0.07$ & $0.96 \pm 0.08$ & $<0.001$ \\
\hline $\mathrm{BF} \%$ & $41.01 \pm 9.79$ & $30.92 \pm 9.27$ & $<0.001$ \\
\hline Uric acid (mg/dL) & $7.85 \pm 5.33$ & $7.22 \pm 1.54$ & 0.363 \\
\hline HDL-c (mg/dL) & $50.30 \pm 18.02$ & $42.24 \pm 12.14$ & 0.003 \\
\hline LDL-c (mg/dL) & $109.61 \pm 45.83$ & $91.13 \pm 31.47$ & 0.008 \\
\hline Total Cholesterol (mg/dL) & $195.61 \pm 55.97$ & $169.76 \pm 42.03$ & 0.003 \\
\hline Triglycerides (mg/dL) & $179.63 \pm 104.11$ & $176.4 \pm 98.32$ & 0.867 \\
\hline Fasting Glucose Diabetics (mg/dL) & $147.55 \pm 89.48$ & $138.78 \pm 61.00$ & 0.592 \\
\hline Fasting Glucose Non-diabetics (mg/dL) & $102.31 \pm 28.95$ & $98.81 \pm 15.32$ & 0.527 \\
\hline HbA1c Diabetics (\%) & $7.67 \pm 1.77$ & $7.80 \pm 1.97$ & 0.753 \\
\hline HbA1c Non-diabetics (\%) & $5.82 \pm 1.09$ & $5.88 \pm 1.57$ & 0.894 \\
\hline SBP Hypertensive (mmHg) & $135.06 \pm 20.34$ & $136.81 \pm 24.39$ & 0.642 \\
\hline SBP Non-hypertensive & $136.87 \pm 17.10$ & $133.57 \pm 11.50$ & 0.593 \\
\hline DBP Hypertensive (mmHg) & $76.70 \pm 14.30$ & $76.50 \pm 12.31$ & 0.925 \\
\hline DBP Non-hypertensive & $78.75 \pm 6.40$ & $78.57 \pm 10.27$ & 0.965 \\
\hline
\end{tabular}




\begin{tabular}{|c|c|c|c|c|c|}
\hline Variable & & Female n(\%) & $\begin{array}{l}\text { Male } \\
\text { n (\%) }\end{array}$ & Total & p value ${ }^{\epsilon}$ \\
\hline \multirow[b]{2}{*}{ Sample } & $<60$ years & $20(27.0)$ & $14(14.3)$ & $34(19.8)$ & \multirow[b]{2}{*}{0.052} \\
\hline & $\geq 60$ years & 54 (73.0) & 84 (85.7) & 138 (80.2) & \\
\hline \multirow{2}{*}{ Physical activity } & > 150 minutes/ week & $28(37.8)$ & $37(37.8)$ & $65(37.8)$ & \multirow{2}{*}{1.000} \\
\hline & $<150$ minutes/ week & $46(62.2)$ & $61(62.2)$ & $107(62.2)$ & \\
\hline \multirow{2}{*}{ Smoking } & Yes & $2(2.7)$ & $15(15.3$ & $17(9.9)$ & \multirow{2}{*}{0.008} \\
\hline & No & $72(97.3)$ & $83(84.7)$ & 155 (90.1) & \\
\hline \multirow{2}{*}{ Use of alcohol } & Yes & $6(8.1)$ & $16(16.3)$ & $22(12.8)$ & \\
\hline & No & 68 (91.9) & $82(83.7)$ & $150(87.2)$ & 0.166 \\
\hline \multirow{2}{*}{ SAH } & Present & $66(89.2)$ & $84(85.7)$ & $150(87.2)$ & 0.646 \\
\hline & Absent & $8(10.8)$ & $14(14.3)$ & $22(12.8)$ & \multirow{3}{*}{0.646} \\
\hline \multirow{2}{*}{$\mathrm{DM}$} & Present & $38(51.4)$ & $54(55.1)$ & $92(53.5)$ & \\
\hline & Absent & $36(48.6)$ & $44(44.9)$ & $80(46.5)$ & \\
\hline \multirow{2}{*}{ SAH and DM } & Present & $36(48.6)$ & $50(51.0)$ & $86(50.0)$ & \multirow[t]{2}{*}{0.878} \\
\hline & Absent & $38(51.4)$ & $48(49.0)$ & $86(50.0)$ & \\
\hline \multirow{4}{*}{ CKD Stage } & $3 \mathrm{~A}$ & $9(12.2)$ & $17(17.5)$ & $26(15.2)$ & \multirow{4}{*}{0.788} \\
\hline & 3B & $39(52.7)$ & 49 (50.5) & $88(51.5)$ & \\
\hline & 4 & $21(28.4)$ & $26(26.8)$ & $47(27.5)$ & \\
\hline & 5 & $5(6.8)$ & $5(5.2)$ & $10(5.8)$ & \\
\hline \multirow{2}{*}{ BMI Adults $\left(\mathrm{Kg} / \mathrm{m}^{2}\right)$} & $<25$ & $3(15.0)$ & $3(21.4)$ & $6(17.6)$ & \multirow[t]{2}{*}{0.672} \\
\hline & $\geq 25$ & $17(85.0)$ & $11(78.6)$ & $28(82.4)$ & \\
\hline \multirow{2}{*}{$\begin{array}{l}\text { BMI Elderly } \\
\left(\mathrm{Kg} / \mathrm{m}^{2}\right)\end{array}$} & $<27$ & $16(29.6)$ & $38(45.8)$ & $54(39.4)$ & \multirow[t]{2}{*}{0.074} \\
\hline & $\geq 27$ & 38 (70.4) & 45 (54.2) & 83 (60.6) & \\
\hline \multirow{2}{*}{$\mathrm{WC}(\mathrm{cm})$} & $q<80 ; \hat{\jmath}<94$ & $6(8.1)$ & 35 (35.7) & $41(23.8)$ & \multirow{2}{*}{$<0.001$} \\
\hline & $\uparrow \geq 80 ; \hat{\jmath} \geq 94$ & 68 (91.9) & $63(64.3)$ & $131(76.2)$ & \\
\hline \multirow[b]{2}{*}{ WHR (cm) } & 우 $<0.85 ;$ ठㅅ $<1.0$ & $12(16.2)$ & $59(60.2)$ & $71(41.3)$ & \multirow[b]{2}{*}{$<0.001$} \\
\hline & $\phi \geq 0.85 ; \hat{\jmath} \geq 1.0$ & $62(83.8)$ & $39(39.8)$ & 101 (58.7) & \\
\hline \multirow[b]{2}{*}{ Body fat (\%) } & ㅇ $<27 ;$ Љ $<17$ & $6(8.1)$ & $7(7.3)$ & $13(7.6)$ & \multirow[t]{2}{*}{1.000} \\
\hline & $\uparrow \geq 27 ; \partial^{\lambda} \geq 17$ & 68 (91.9) & 89 (92.7) & 157 (92.4) & \\
\hline \multirow{2}{*}{$\begin{array}{l}\text { Uric Acid } \\
(\mathrm{mg} / \mathrm{dL})\end{array}$} & 우 $<6 ; \delta^{\lambda}<7$ & $14(18.9)$ & $32(32.7)$ & $46(26.7)$ & \multirow{2}{*}{0.056} \\
\hline & $+q \geq 6 ; \delta^{\Uparrow} \geq 7$ & $60(81.1)$ & $66(67.3)$ & $126(73.3)$ & \\
\hline \multirow{2}{*}{ HDL-c (mg/dL) } & $>60$ & $43(58.1)$ & 43 (43.9) & $86(50.0)$ & \multirow{2}{*}{0.090} \\
\hline & $<40$ & 31 (41.9) & $55(56.1)$ & $86(50.0)$ & \\
\hline \multirow{2}{*}{ LDL-c (mg/dL) } & $<160$ & $66(89.2)$ & $94(95.9)$ & $160(93)$ & \\
\hline & $\geq 160$ & $8(10.8)$ & $4(4.1)$ & $12(7.0)$ & 0.129 \\
\hline
\end{tabular}




\begin{tabular}{|c|c|c|c|c|c|}
\hline Variable & & Female $n(\%)$ & $\begin{array}{l}\text { Male } \\
\text { n (\%) }\end{array}$ & Total & p value ${ }^{\epsilon}$ \\
\hline \multirow{2}{*}{ TC (mg/dL) } & $<240$ & $62(83.8)$ & $94(95.4)$ & $156(90.7)$ & \multirow{2}{*}{0.008} \\
\hline & $\geq 240$ & $12(16.2)$ & $4(4.1)$ & $16(9.3)$ & \\
\hline \multirow{2}{*}{ TG (mg/dL) } & $<200$ & $56(75.7)$ & $74(75.5)$ & $130(75.6)$ & \multirow{2}{*}{0.790} \\
\hline & $\geq 200$ & $18(24.3)$ & $24(24.5)$ & 42 (24.4) & \\
\hline \multirow{3}{*}{ Glucose (mg/dL) } & $\begin{array}{c}\mathrm{DM}<126 ; \\
\text { No } \mathrm{DM}<100\end{array}$ & $47(63.5)$ & $58(59.2)$ & $105(61)$ & \multirow{3}{*}{0.636} \\
\hline & $\mathrm{DM}>126$ & & & & \\
\hline & No DM $\geq 100$ ) & $27(36.5)$ & $40(40.8)$ & $67(39)$ & \\
\hline \multirow{3}{*}{$\mathrm{Hb} 1 \mathrm{Ac}(\%)$} & $\begin{array}{c}\mathrm{DM}<7 ; \\
\text { No } \mathrm{DM}<5.3\end{array}$ & $17(23.0)$ & $30(30.6)$ & 47 (27.3) & \multirow{3}{*}{0.302} \\
\hline & & & & & \\
\hline & $\begin{array}{c}\mathrm{DM} \geq 7 ; \\
\text { No } \mathrm{DM}>5.3\end{array}$ & $57(77.0)$ & $68(69.4)$ & $125(72.7)$ & \\
\hline \multirow{3}{*}{ Framingham score CVD risk } & Low $(<10 \%)$ & $30(40.5)$ & $44(44.9)$ & $74(43.0)$ & \multirow{3}{*}{0.267} \\
\hline & Moderate (10-20\%) & $31(41.9)$ & $30(30,6)$ & $61(35.5)$ & \\
\hline & High $(>20 \%)$ & $13(17.6)$ & $24(24.5)$ & $37(21.5)$ & \\
\hline
\end{tabular}

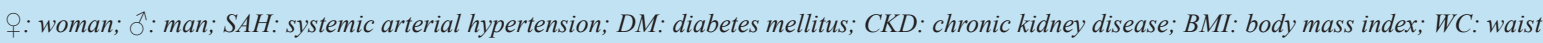
circumference; WHR: waist-hip ratio; HDL-c: high density lipoprotein; LDL-c: low density lipoprotein; TC: total cholesterol, TG: triglycerides; Hb1Ac: glycated hemoglobin; CVD: cardiovascular disease.

$€$ Pearson's Chi-square test.

Regarding the BMI classification, $82.4 \%$ of all the sample and $60.6 \%$ of the elderly were overweight. Elevated WC and WHR were highly prevalent among women $(91.9 \%$ and $83.8 \%$, respectively), and significantly higher than men (64.3\% and $39.8 \%$, respectively). Furthermore, a high BF\% was found in $92.4 \%$ of the sample. Regarding biochemical tests, the high prevalence of high uric acid levels stood out, both in women and men (81.1\% and $67.3 \%$, respectively).

As for the risk of CVD, according to the Framingham score, $43 \%$ of the sample was at low risk, followed by $35.5 \%$ at medium risk and $21.5 \%$ at high risk of developing CVD in ten years.

The factors associated with cardiovascular risk, according to the Framingham score are shown in Table 3. It was verified that individuals with an income above the minimum wage and adults with a high BMI had a higher risk of developing CVD.

\section{Discussion}

The main cause of death in patients in stage 1 CKD is $\mathrm{CVD}^{24}$ and the associated risks include traditional ones, such as old age, male gender, arterial hypertension, elevated LDL-c, reduced HDL-c, DM, smoking, sedentary lifestyle, and non-traditional ones such as decreased GRF, anemia, type of CKD, among others. ${ }^{25}$

Most of the sample was composed of male adults, older than 60 years. This finding can be justified by the fact that older adults are at relatively higher risk for developing CKD, due to physiological decrease in GFR and kidney injury secondary to aging and associated chronic disease, such as DM and hypertension. ${ }^{26}$ Moreover, according to Bregman, ${ }^{12}$ male sex is a non-modifiable risk factor for the progress of CKD.

Low income and low education, as observed in our study group (median per capita income of $\mathrm{R} \$ 880.00$ and incomplete elementary school in $66.3 \%$ of participants), are determining factors for the occurrence of CKD and must be analyzed for screening and monitoring of the disease. ${ }^{9,27}$

In our study, the patients with CKD had a high prevalence of arterial hypertension (87.2\%) and DM $(53.5 \%)$, and $50 \%$ of them had both diseases concomitantly, which is a risk factor for CVD. Similar findings were 
Table 3- Factors associated with cardiovascular risk, according to the Framingham score

\begin{tabular}{|c|c|c|c|c|c|}
\hline \multirow[t]{2}{*}{ Variable } & & \multicolumn{3}{|c|}{ Framingham score classification } & \multirow{2}{*}{$\mathrm{p}$ value } \\
\hline & & Low n (\%) & Medium n (\%) & High n (\%) & \\
\hline \multirow{2}{*}{ Sample } & Adults $<60$ years old & $14(41.2)$ & $13(38.2)$ & $7(20.6)$ & \multirow{2}{*}{0.931} \\
\hline & Adults $\geq 60$ years old & $60(43.5)$ & $48(34.8)$ & $30(21.7)$ & \\
\hline \multirow{2}{*}{ Income } & Less than minimum wage & $50(47.6)$ & $40(38.1)$ & $15(14.3)$ & \multirow{2}{*}{0.015} \\
\hline & More than minimum wage & $24(35.8)$ & $21(31.3)$ & $22(32.8)$ & \\
\hline \multirow{2}{*}{ Education } & Incomplete elementary school & $57(44.5)$ & $47(36.7)$ & $24(18.8)$ & \multirow{2}{*}{0.444} \\
\hline & Complete elementary school & $17(39.5)$ & $14(32.6)$ & $12(27.9)$ & \\
\hline \multirow{2}{*}{ Physical activity } & Yes (> 150 minutes/week) & $27(41.5)$ & $20(30.8)$ & $18(27.7)$ & \multirow{2}{*}{0.278} \\
\hline & No (<150 minutes/week) & $47(43.9)$ & $41(38.3)$ & $19(17.8)$ & \\
\hline \multirow{4}{*}{ CKD stages } & $3 \mathrm{~A}$ & $11(42.3)$ & $9(34.6)$ & $6(23.1)$ & \multirow{4}{*}{0.990} \\
\hline & $3 \mathrm{~B}$ & $39(44.3)$ & $32(36.4)$ & $17(19.3)$ & \\
\hline & 4 & $19(40.4)$ & $17(36.2)$ & $11(23.4)$ & \\
\hline & 5 & $4(40.0)$ & $3(30.0)$ & $3(30.0)$ & \\
\hline \multirow{2}{*}{ BMI Adults < 60 years old $\left(\mathrm{Kg} / \mathrm{m}^{2}\right)$} & Appropriate & $5(83.3)$ & $0(0.0)$ & $1(16.7)$ & \multirow{2}{*}{0.050} \\
\hline & High & $9(32.1)$ & $13(46.4)$ & $6(21.4)$ & \\
\hline \multirow{2}{*}{ BMI Adults $\geq 60$ years old $\left(\mathrm{Kg} / \mathrm{m}^{2}\right)$} & Appropriate & $26(48.1)$ & $15(27.8)$ & $13(24.1)$ & \multirow{2}{*}{0.353} \\
\hline & High & $34(41.0)$ & $33(39.8)$ & $16(19.3)$ & \\
\hline \multirow{2}{*}{$\mathrm{WC}(\mathrm{cm})$} & $\uparrow<80 ; \precsim<94$ & $24(58.5)$ & $10(24.4)$ & $7(17.1)$ & \multirow{2}{*}{0.068} \\
\hline & 오 $\geq 80 ; \precsim \geq 94$ & $50(38.2)$ & $51(38.9)$ & $30(22.9)$ & \\
\hline \multirow{2}{*}{ WHR } & $q<0.85 ; \hat{\jmath}<1.0$ & $37(52.1)$ & $19(26.8)$ & $15(21.1)$ & \multirow{2}{*}{0.086} \\
\hline & $q \geq 0.85 ; \hat{o} \geq 1.0$ & $37(36.6)$ & $42(41.6)$ & $22(21.8)$ & \\
\hline \multirow{2}{*}{$\mathrm{BF}(\%)$} & $q<27 ; \hat{0}<17$ & $6(8.1)$ & $2(3.3)$ & $5(14.3)$ & \multirow{2}{*}{0.146} \\
\hline & 우 $\geq 27 ; \delta^{\lambda} \geq 17$ & $68(91.9)$ & $59(96.7)$ & $30(85.7)$ & \\
\hline
\end{tabular}

CKD: chronic kidney disease; BMI: body mass index; WC: waist circumference; WHC: waist-hip ratio; BF: body fat; $€$ Pearson's Chi-square test.

reported in a survey conducted by Pinho et al., ${ }^{28}$ in a general medical clinic in São Paulo, in which $75.2 \%$ of CKD patients were hypertensive and $49.5 \%$ diabetic. ${ }^{28}$ Our population (both hypertensive and non-hypertensive individuals) had high mean SBP and DBP values according to the reference values. This is a positive finding, since the control of hypertension is relevant to delay the progression of CKD and possibly the development of CVD. ${ }^{29}$

Regarding smoking habit, it was more prevalent among men than women, as reported in a study carried out in São Paulo, Brazil, in which $36.4 \%$ of men were smokers. Smoking is one of the most important factors for acute myocardial infarction. ${ }^{29}$
The high prevalence of physical inactivity (62.2\%) is worrying, since physical inactivity, added to other traditional cardiovascular risk factors, promotes accelerated atherosclerosis and early mortality. ${ }^{30}$ A high prevalence of physical inactivity $(74 \%)$ was also identified in patients with CKD under conservative treatment by Fortes et al. ${ }^{31}$

Overweight in patients with CKD can increase renal plasma flow and intraglomerular pressure, which, in turn, increases cardiac output. ${ }^{31,32}$ Increased central adiposity demarcated by high WHR is associated with metabolic complications. ${ }^{9}$ In the present study, there was a prevalence of overweight of $82.4 \%$ in adults ( $<60$ years old) 
and of $60.6 \%$ in the elderly (60 years old), and WHR values were higher in females, in agreement with a study carried out in Brusque, a city in Santa Catarina State, Brazil. ${ }^{33}$

BMI was high in both sexes and in all age groups and correlated with cardiovascular complications. However, $\mathrm{BMI}$ is considered a controversial marker, since it does not discriminate between the different components of the body (lean and fat mass) and does not describe the fat distribution (visceral fat and subcutaneous fat). ${ }^{8}$ For this reason, the use of WC is recommended, which has been suggested as a direct predictor of all-cause mortality from CVD. ${ }^{7}$ High values of WC was found in most patients $(76.2 \%)$, with higher prevalence in women than men $(\mathrm{p}<0.001)$, similar to previously reported data. ${ }^{34}$

Alarming prevalence of increased $\mathrm{BF} \%$ was found in men $(92.7 \%)$ and women $(91.9 \%)$. This fact draws attention, since excess body fat is associated with cardiovascular risk factors, such as metabolic syndrome, DM, hypertension, hypercholesterolemia and atherosclerosis. ${ }^{34}$

Dyslipidemia is common in CKD and its presence can contribute to increase cardiovascular risk, ${ }^{35}$ since elevated TG and reduced HDL-c are independent predictors of cardiometabolic episodes ${ }^{36}$. Regarding elevated LDL-c, data from the National Health and Nutrition Examination Survey (NHANES 1999-2006) demonstrated a $46 \%$ prevalence of this lipid alteration in adults with stages 1-2 CKD and $80 \%$ with CKD stages 3 and $4 .{ }^{37}$ Despite these findings, in the present study, the values of serum lipid parameters were within or close to the recommended values, similar to the results found in the study by Fortes et al. ${ }^{31}$

Regarding uric acid levels, these were above the recommended levels. It is known that hyperuricemia is highly prevalent in CKD; however, it is still unclear whether uric acid is merely a marker of comorbidities and kidney damage or whether it is a factor for cardiovascular outcomes. ${ }^{38}$ According to a cohort study by Wan-Chun Liu, which evaluated 3,749 patients with stages 3-5 CKD for three years, hyperuricemia is a risk factor for cardiovascular events in these patients.

The values found for fasting blood glucose and $\mathrm{HbA1C}$ were higher than recommended. According to Hage, ${ }^{4}$ the lack of glycemic control is associated with the progression of CKD and cardiovascular mortality. To prevent these outcomes, it is recommended to keep HbA1C at levels below $7.0 \%$ and postprandial glycemia below $140 \mathrm{mg} /$ dL40 for diabetics, and from 3.6 to $5.3 \%$ and less than $100 \mathrm{mg} / \mathrm{dL20}$, respectively, for non-diabetics.
In relation to GFR, it was shown that for each decrease of $10 \mathrm{~mL} / \mathrm{min} / 1.73 \mathrm{~m}$ in the GFR, there is a $10 \%$ increase in the relative risk of death or non-fatal cardiovascular complication. ${ }^{39}$ In the present study, patients were mostly in stage $3 \mathrm{~B}$, indicating that they should continue with nutritional monitoring and undergo treatment to prevent the progress to CKD stage 5 or even develop cardiovascular complications.

Regarding the 10-year cardiovascular risk estimated using the Framingham score, $43 \%$ of the sample was at low risk, $35.5 \%$ at medium risk and $21.5 \%$ at high risk. These results are similar to those reported by Cesarino. ${ }^{39}$ These findings can be used by health professionals to improve treatment adherence and develop strategies to the reduce risk and morbidity and mortality of CVD.

A limitation of the study is the fact that it is a crosssectional study, which makes it impossible to infer that patients at cardiovascular risk will in fact develop CVD. However, despite its limitations, the relevance of the study lies in its originality and importance of the theme.

Assessing cardiovascular risk factors in patients with CKD is of paramount importance, since this condition is commonly concomitant with many factors associated with an increased risk of cardiovascular diseases, such as older age, comorbidities like DM and hypertension, and overweight. Thus, a multidisciplinary approach is needed, to assist in the prevention and control of cardiovascular mortality in this population. since Adherence to healthy eating patterns is a protective factor for renal function, helping to prevent the development of chronic diseases, thereby improving the prognosis and favoring a better quality of life.

\section{Conclusions}

There was a high prevalence of cardiovascular risk factors in the population studied, such as physical inactivity, presence of comorbidities (hypertension and $\mathrm{DM})$, increased $\mathrm{BMI}, \mathrm{WC}, \mathrm{WHR}$ and $\mathrm{BF} \%$, and elevated uric acid and high HbA1C levels. Nevertheless, 57\% of the sample were at medium or high risk of developing CVD in 10 years, according to the Framingham score. Individuals with a per capita income above the minimum wage and high BMI had a higher 10-year risk of developing CVD.

Assessing cardiovascular risk factors in patients with CKD is important and allows guiding the conduct of health professionals to prevent mortality from cardiovascular causes. 


\section{Author contributions}

Conception and design of the research: Pereira PML, Bastos MG, Candido APC. Acquisition of data: Oliveira CFM, Pereira PML, Soares IT, Monteiro MG. Analysis and interpretation of the data: Oliveira CFM, Pereira PML, Soares IT, Candido APC. Statistical analysis: Oliveira CFM, Pereira PML, Candido APC. Writing of the manuscript: Oliveira CFM, Pereira PML. Critical revision of the manuscript for intellectual content: Pereira PML, Soares IT, Monteiro MG, Bastos MG, Candido APC.

\section{Potential Conflict of Interest}

No potential conflict of interest relevant to this article was reported.

\section{References}

1. Kidney Disease: Improving Global Outcomes (KDIGO) CKD Work Group. KDIGO 2012 Clinical Practice Guideline for the Evaluation and Management of Chronic Kidney Disease. KidneyIntSuppl. 2013; 3(1): 5-14.

2. Bastos, R.M.R. Prevalência da doença renal crônica nos estágios 3,4 e 5 em adultos. Rev Assoc Med Bras.2009; 55(1):40-4.

3. Sociedade Brasileira de Nefrologia. Censo de diálise [serial online] SBN; 2012[cited 2018 jan. 29]. 1:[1 screens].Available from: URL: https://sbn.org.br

4. Hage FG. The scope of coronary heart disease in patient swith chronic kidney disease. J Am Coll Cardiol. 2009; 53(23):2129-40.

5. Van Der Velde M, Astor BC , K Matsushita , Gansevoort RT, Levey AS , Jong PE et al. Lower estimated glomerular filtration rate and higher albuminuria are associated with all-cause and cardiovascular mortality. A collaborative meta-analysis of high-risk population cohorts. Kidney Int. 2011;79(12):1341-52.

6. Martin, C. L. A doença renal como fator de risco cardiovascular. Arquivos brasileiros de cardiologia. 2005;85(6):432-6.

7. Postorino, M. et al. Abdominal obesity and all-cause and cardiovascular mortality in end-stage renal disease. J Am Coll Cardiol. 2009;53(15):1265-72

8. Gohda T, Gotoh H, Tanimoto M, Sato M, Io H, Kaneko K, et al. Relationship between abdominal fatac cumulation and insulin resistance in hemodialysis patients. Hypertens Res 2008; 31(1):83-8.

9. WHO, World Health Organization. Obesity: Preventing and managing the global epidemic - Report of a WHO consultation on obesity. Geneva; 2000.

10. Postorino M, Marino C, Tripepi G, Zoccali C. Abdominal obesity modifies the risk of hypertriglyceridemia for all-cause and cardiovascular mortality in hemodialysis patients. International Society of Nephrology. 2011;79(7):765-72.

11. Liu WC, Kuo MC, Chang JM, Hwang SJ , Chen HC, Chiu YW et al, Association of Hyperuricemiawith Renal Outcomes, Cardiovascular Disease, and Mortality. The American Society of Nephrology. 2012;7(4):541-8

12. Bregman R. Prevenção da progressão da doença renal crônica. J. Bras. Nefrol. 2004;26(3 suppl. 1):11- 4.

\section{Sources of Funding}

There were no external funding sources for this study.

\section{Study Association}

This study is not associated with any thesis or dissertation work.

\section{Ethics approval and consent to participate}

This study was approved by the Ethics Committee of the Hospital Universitário da Universidade Federal de Juiz de Fora under the protocol number 1384.797. All the procedures in this study were in accordance with the 1975 Helsinki Declaration, updated in 2013. Informed consent was obtained from all participants included in the study.

13. Framingham Heart Study. A Project of National Heart, Lung and Blood Instituteand Boston University[serial online] 2018 [cited 2018 Set 28];1:[6 screens].Available from: URL: https://www.framinghamheartstudy. org/fhs-risk-functions/hard-coronary-heart-disease-10-year-risk/

14. Lloyd Jones DM; Wison PW, Larson MG, Beiser A, Leipe EP, D' Agostino RB, et al. Framingham risk score and prediction of life time risk for coronary heart disease. Am J Cardiol. 2004;94(1):20-4.

15. Instituto Brasileiro de Geografia e Estatística (IBGE). Estimativas da população, 2015. [Citado em 2017 jan 10]. Available from: URL: https://www.ibge.gov.br/estatisticas/sociais/populacao/9103estimativas-de-populacao.html?edicao $=17283 \& \mathrm{t}=$ downloads

16. Hill NR, Fatoba ST,Oke JL, Hirst JA, O'Callaghan CA, Lasserson DS,et al. Global Prevalence of Chronic Kidney Disease. - A Systematic Review and Meta-Analysis. PLoS One. 2016;11(7):1-18.

17. Pescatello L.S, Arena R, Riebe D, Thompson P.D ACSM's guidelines for exercise testing and prescription. 9.ed. Baltimore: Lippincott Williams \& Wilkins; 2014. p.2-18.

18. Lipschitz, D.A. Screening for nutritional status in the elderly. Prim Care. 1994;21(1):55-67.

19. Lohman T.G, Champaign, I.L. Advances in body composition assessment. Champaign, IL: Human Kinetics Publishers, 1992.

20. Nemer, A.G.A.; Neves, F.J.; Ferreira, J.E.S.editors; Manual de solicitação e interpretação de exames laboratoriais, Rio de Janeiro: Revinter, 2010

21. MVB Malachias, FL Plavnik, CA Machado, D Malta, LCN Scala, S Fuchs. Arquivos Brasileiros de Cardiologia. $7^{\circ}$ Diretriz Brasileira de hipertensão arterial [serial online] Sociedade Brasileira de Cardiologia; 2016.117(3):3-83.

22. Levey, AS, Stevens LA, Schmid CH, Zhang YL, Castro AF 3rd, Feldman HI, et al.; CKD-EPI (Chronic Kidney Disease Epidemiology Collaboration). A new equation to estimate glomerular filtration rate. Ann Intern Med. 2009; 150(9):604-12.

23. Brasil. Ministério da Saúde. Secretaria de Atenção à Saúde. Estratégia para o cuidado da pessoa com doença crônica hipertensão arterial sistêmica [serial online]. Brasília, 2013 (Cadernos de Atenção Básica). [cited 2018 Out 24];37:[130 screens].Available from: URL: http://bvsms.saude.gov. br/bvs/publicacoes/estrategias_cuidado_pessoa_doenca_cronica.pdf 
24. Sarnak M.J, Levey AS, Schoolwerth A.C, Coresh J, Culleton B, Hamm L.L, et al. Kidney disease as a risk factor for development of cardiovascular disease a statement from the American Heart Association Councilson Kideney in Cardiovascular Disease, High Blood Pressures Research, Clinical Cardiology, and Epidemiology and Prevention. Hypertension. 2003; 42(5):1050-65.

25. Ernesto L. S, Mark, L.L, Johannes, F.E.M. Chronic Kidney Disease Effects on the Cardiovascular System. Circulation. 2007; 116(1):85-97.

26. K/doqi clinical practice guidelines for chronic kidney disease: evaluation, classification And stratification [editorial]. Am J Kidney Dis. 2002;39(2 Suppl 1):S1-266.

27. Bastos, MG, Kirsztajn, GM. Doença renal crônica: importância do diagnóstico precoce, encaminhamento imediato e abordagem interdisciplinar estruturada para melhora do desfecho em pacientes ainda não submetidos à diálise. J Bras Nefrol, 2011;33(1):93-108.

28. Bruce MA, Beech MB, Sims M, Brown TN, Wyatt SB, Taylor HA, et al. Social environmental stressors, psychological factors and kidney disease. J Investig Med, 2009;57(4):583-9.

29. Pinho NA, Silva GV, Pierin MG. Prevalência e fatores associados à doença renal crônica em pacientes internados em um hospital universitário na cidade de São Paulo, SP, Brasil. J Bras Nefrol. 2015; 37(1): 91-7.

30. James M.T, Hemmelgarn B.R, Tonelli M. Early recognition and prevention of chronic kidney disease. Lancet 2010; 375(9722):1296-309.

31. Fortes A. A, Lima, G.M.H, Santana, G.T, Barbosa, R.L, Luiz, N.G.A, Pereira, C.M.E, et al. Razão TG/HDL-c, indicadores antropométricos e bioquímicos de risco cardiovascular no renal crônico em tratamento conservador. Nutr clin diet hosp. 2017; 37(4):10-6
32. Junior G.B.S, Bentes, A.S.N, Daher, E. F, Matos, S. M.A. Obesidade e doença renal. J Bras Nefrol. 2017; 39(1):65-9.

33. Rosini N, Machado, M. J, Xavier, H. T. Study of the prevalence and multiplicity of cardiovascular risk factors in hypertensive individuals from the city of Brusque, SC, Brazil. ArqBrasCardiol.2006; 86(3):219-22.

34. Elsayed E.F, Tighiouart H, Weiner DE, Griffith J, Salem D, Levey AS, et al Waist-to-hip ratio and body mass index as risk factors for cardiovascular events in CKD. Am J Kidney Dis. 2008; 52:49-57.

35. Akpan E.E, Ekrikpo, U. E, Effa, E. E, Udo, A. I. A, Kadiri, S. Assessment of dyslipidemia in pre-dialysis patients in south-west Nigeria. NigerMed J. 2014; 55(3):214-9.

36. Salazar M.R, Carbajal H.A, Espeche W.G, Leiva Sisnieguez C.E, Balbín E, Dulbecco C.A et al. Relation Among the Plasma Triglyceride/HighDensity Lipoprotein Cholesterol Concentration Ratio, Insulin Resistance, and Associated Cardio-Metabolic Risk Factors in Men and Women. Am J Cardiol. 2012; 109(12):1749 -53.

37. Snyder JJ, Foley, N.R, Collins, J. A. Prevalence of CKD in the United States: a sensitivity analysisus ing the National Health and Nutrition Examination Survey (NHANES) 1999-2004. Am J KidneyDis. 2009; 53(2):218-28.

38. Lordsleem A.Gueiros, A.P.S, Gueiros, J.E.B, Filho,B.M, Victor,E.G. Cardiac evaluation of patients with chronic kidney disease: what lessons?. J Bras Nefrol. 2012; 34(1):8-15.

39. Cesarino, B.C, Borges, P.P, Ribeiro, M.H.C.R, Ribeiro, F.D, Kusumota, L. Avaliação do risco cardiovascular de pacientes renais crônicos segundo critérios de Framingham. Acta Paul Enferm. 2013; 26(1):101-7. 